\title{
The effects of germanium and selenium on growth, metalloid accumulation and ergosterol content in mushrooms: experimental study in Pleurotus ostreatus and Ganoderma lucidum
}

\author{
Marek Siwulski ${ }^{1}$ Sylwia Budzyńska ${ }^{2} \cdot$ Piotr Rzymski $^{3} \cdot$ Monika Gąsecka $^{2} \cdot$ Przemysław Niedzielski $^{4} \cdot$ Pavel Kalač $^{5}$. \\ Mirosław Mleczek
}

Received: 5 February 2019 / Revised: 29 April 2019 / Accepted: 5 May 2019 / Published online: 24 May 2019

(c) The Author(s) 2019

\begin{abstract}
The aim of this study was to examine the effects of substrate supplementation with germanium (Ge) and selenium (Se), alone or combined, on the growth, element accumulation and ergosterol content in the fruiting bodies of the mushroom species Ganoderma lucidum and Pleurotus ostreatus. Both species were grown in four independent experimental systems with different concentrations of germanium powder $(1,5$ and $10 \mathrm{mM})$, selenite [Se(IV)] and selenate [Se(VI)] $(0.1,0.4$ and $0.8 \mathrm{mM}$ of each Se species). Se supplementation caused no observable changes to morphology while the addition of Ge induced changes in size and/or colour, especially for $P$. ostreatus. A synergistic effect of Ge supplementation on Se accumulation in fruiting bodies of G. lucidum was observed only at the two highest levels of supplementation with both elements. Even though inorganic Se was used to enrich the experimental substrates, organic Se compounds dominated in the fruiting bodies. Increasing levels of $\mathrm{Ge}$ in the substrates elevated the content of organic selenium in the fruiting bodies of G. lucidum. No such trend was recorded in P. ostreatus. The maximum mean Ge levels in P. ostreatus and G. lucidum reached up to 70 and $80 \mathrm{mg} \mathrm{kg}^{-1}$, respectively. However, the bioaccessibility of this element was low, in the range 5.4-6.6\% (P. ostreatus) and 0.4-7.6\% (G. lucidum). Ergosterol content in the fruiting bodies of both species displayed the highest values in all the experimental systems supplemented with Se. The addition of $\mathrm{Ge}$ and $\mathrm{Se}+\mathrm{Ge}$ resulted in losses of ergosterol content in comparison to cultivation with Se supplementation and control. The obtained results show the significant role of $\mathrm{Ge}-\mathrm{Se}$ interaction in the accumulation of these elements in the studied mushroom species.
\end{abstract}

Keywords Edible mushrooms $\cdot$ Supplementation of substrate $\cdot$ Germanium $\cdot$ Selenium $\cdot$ Fortification of fruiting bodies

\section{Introduction}

Mirosław Mleczek

miroslaw.mleczek@up.poznan.pl

1 Department of Vegetable Crops, Poznan University of Life Sciences, Poznan, Poland

2 Department of Chemistry, Poznan University of Life Sciences, Poznan, Poland

3 Department of Environmental Medicine, University of Medical Sciences, Poznan, Poland

4 Faculty of Chemistry, Adam Mickiewicz University in Poznań, Poznan, Poland

5 Department of Applied Chemistry, Faculty of Agriculture, University of South Bohemia, Ceske Budejovice,

Czech Republic
The fruiting bodies of approximately 200 wild-growing and cultivated mushroom species are consumed in many countries as a delicacy but also due to increased interest in their biological qualities and potential use as functional foods or a source of novel pharmaceuticals [1-3].

Mushrooms are well known for their abilities to accumulate various metals and metalloids in their fruiting bodies, including those significant for human nutrition as well as toxic elements. This phenomenon can be used in biofortification strategies in mushroom cultivation and result in their increased nutritional value or biological activity. A number of studies have already demonstrated that this approach can be employed to enrich the fruiting bodies of selected species with elements such as copper in Ganoderma lucidum [4]; iron $(\mathrm{Fe})$ in Pleurotus ostreatus, P. cornucopiae, P. djamor, 
P. pulmonarius or $P$. djamor v. roseus [5]; lithium (Li) in $G$. lucidum, P. eryngii and P. ostreatus [6, 7]; potassium (K) in $P$. eryngii, Flammulina velutipes or Hypsizygus marmoreus [8]; selenium (Se) in A. bisporus, P. eryngii, P. ostreatus, Pholiota nameko $[9,10]$ and zinc $(\mathrm{Zn})$ in $G$. lucidum and $P$. ostreatus [11]. Particular attention has been paid to substrate supplementation with inorganic Se salts as such an approach appears to potentially increase antioxidant, immunomodulatory and anticancer activities of selected mushrooms species $[12,13]$.

On the other hand, the abilities of mushrooms to uptake and concentrate elements from the ambient environment requires the establishment of high standards of cultivation conditions to minimize any risk of contamination and ensure consumer safety $[1,14]$. A number of experimental studies have already shown that selected cultivated species can accumulate toxic metals (e.g. $\mathrm{Hg}$ ) or metalloids (e.g. As) if there are high levels available in substrate, and that this can further affect the nutritional value of fruiting bodies [15, 16].

For this reason, several recent studies have investigated the content of toxic or potentially toxic elements in various cultivated mushroom species originating from a variety of geographical locations $[14,17]$. Most of these studies have found levels of germanium $(\mathrm{Ge})$ below detection limits while some others have detected it at levels ranging from a few $\mu \mathrm{g} \mathrm{kg}^{-1}$ in Phellinus sp. to as much as approx. $1 \mathrm{mg} \mathrm{kg}^{-1}$ in Ganoderma sp. [18, 19]. Considering that $\mathrm{Ge}$ is a rare metalloid which is extracted in its inorganic form from mostly non-ferrous metallic ores for use in semiconductors and other electronic devices, it is likely that its levels in cultivated substrates are generally very low. However, litthe is known about how Ge could affect mushroom growth and chemical composition if it was to occur at an increased level in the ambient environment. There are no documented specific physiological roles of Ge in biological systems, including mushrooms and it is considered as a non-essential element. In humans, inorganic forms of $\mathrm{Ge}\left(\mathrm{Ge}_{\mathrm{in}}\right)$ are associated with toxicity. Experimental models have shown that its organic forms $\left(\mathrm{Ge}_{\text {org }}\right)$ may in turn display antioxidant, immunomodulatory and anticancer properties although the use of Ge-containing supplements is currently disregarded [20].

It is important to study how increased Ge content can affect cultivated mushrooms for various reasons: (1) Ge is used in thousands of electronic applications mostly as a transistor metal, it is produced globally with the highest input from China, the United States, Russia, Taiwan, Belgium, Germany and Canada, while the worldwide use of electronics and production of associated waste is on the rise [21], (2) the other potential input of Ge into the environment is the combustion of coal and lignite, which has been estimated to exceed $\mathrm{Ge}$ emissions from industrial production by two orders of magnitude; consequently a gradual increase in $\mathrm{Ge}$ availability can be expected at certain locations [22], (3) it has been claimed anecdotally by non-scientific sources that mushrooms such as $P$. ostreatus can be a source of biologically active Ge, (4) screening of some commercially available mushrooms belonging to the Ganoderma genus has revealed increased levels of Ge in fruiting bodies [19, 23]. However, information on the kinetics of Ge uptake and accumulation in mushrooms and its potential effects on their growth, morphology, nutritional value and biological activity are literally not known. Apart from studies on Ge uptake, accumulation and associated effects, it is also relevant to investigate whether it can interfere with other elements present in the substrate [24]. In general, a limited number of studies have specifically assessed interactions between elements added to the mushroom substrate [25, 26]. As shown in plants, the presence of Se to a certain threshold level may have beneficial effects in mitigation of stress induced by toxic elements such as cadmium or mercury while at significantly increased Se content additive effects on toxicity may be seen as demonstrated, e.g. in case of lead [27-29]. However, there are essentially no data on how Se could interact with $\mathrm{Ge}$ in plants and mushrooms. Considering that there is an increased interest in Se-enrichment of cultivated mushroom species through substrate supplementation, it appears rational to investigate whether $\mathrm{Se}$ and $\mathrm{Ge}$ can interact with each other, what the potential outcomes of such an effect for cultivated mushrooms might be and whether it could affect the quality of the final product. Additionally, that is also important due to an aspect of the use of mushrooms enriched with ultra-trace elements such as Ge for developing novel dietary supplements and therapies [30].

Therefore, the present study aimed to examine the effects of substrate supplementation with $\mathrm{Se}$ and $\mathrm{Ge}$, alone or in combinations on their accumulation in the fruiting bodies and the content of ergosterol a mushroom provitamin, in $P$. ostreatus and G. lucidum.

\section{Materials and methods}

\section{Characteristics of experimental materials}

The growing substrate was prepared from a mixture of alder and beech sawdust (1:1 vol) supplemented with $20 \%$ of wheat bran, $5 \%$ of corn flour, $3 \%$ of soybean meal, $1 \%$ of chalk and $1 \%$ of gypsum in relation to the sawdust dry matter. The mixture was dampened with distilled water to a moisture content of $45 \%$. Next, the substrate was placed in bags (polypropylene foil) and sterilised at a temperature of $121{ }^{\circ} \mathrm{C}$ for $1 \mathrm{~h}$. As soon as the temperature fell below $25^{\circ} \mathrm{C}$, Se salts were dissolved, and Ge powder was stirred in sterile water. The Se solutions and Ge suspension were added to the substrate, which was mixed intensely in an automatic stirrer for 15 min (POLYMIX PX-SR 90 D, Kinematica 
AG, Littau-Luzern, Switzerland). After the addition of the solutions, the substrate moisture was $60 \%$. Selenium was applied either as sodium hydrogen selenite $\left[\mathrm{NaHSeO}_{3}\right.$; $\mathrm{Se}(\mathrm{IV})]$ or sodium selenate $\left[\mathrm{Na}_{2} \mathrm{SeO}_{4} ; \mathrm{Se}(\mathrm{VI})\right]$, both from Acros Organics (New Jersey, USA), and germanium as Ge powder ( $>99.999 \%$ trace metal basis) from Sigma-Aldrich. The following concentrations of Se and Ge were applied to the substrate: $\mathrm{Se}-0.1,0.4$ and $0.8 \mathrm{mM} \mathrm{L}^{-1}$ of each Se species, $\mathrm{Ge}-1,5$ and $10 \mathrm{mM} \mathrm{dm}^{-1}$. The elements were added in three experimental systems: $\mathrm{S}_{1}[0.1 \mathrm{mM} \mathrm{Se}(\mathrm{IV})+0.1 \mathrm{mM}$ $\mathrm{Se}(\mathrm{VI})$ and $1 \mathrm{mM}$ of $\mathrm{Ge}], \mathrm{S}_{2}[0.4 \mathrm{mM} \mathrm{Se}(\mathrm{IV})+0.4 \mathrm{mM}$ $\mathrm{Se}(\mathrm{VI})$ and $5 \mathrm{mM}$ of Ge] and $\mathrm{S}_{3}[0.8 \mathrm{mM} \mathrm{Se}(\mathrm{IV})+0.8 \mathrm{mM}$ $\mathrm{Se}(\mathrm{VI})$ and $10 \mathrm{mM}$ of Ge]. The substrates with element(s) addition were mixed using a POLYMIX PX-SR 90 D stirrer (KINEMATICA AG, Littau-Luzern, Switzerland) with Pleurotus ostreatus spawn (mycelium on wheat grain) in the amount of $10 \%$ of substrate weight and placed in bags (polypropylene foil, bag size $17 \times 28 \mathrm{~cm}$ ). Each bag contained $400 \mathrm{~g}$ of the substrate. Incubation was conducted at a temperature of $25^{\circ} \mathrm{C}$ and $80-85 \%$ air relative humidity until the substrate had become completely covered with mycelium. The bags were placed in a cultivation chamber with the top part of the foil cutoff. The relative humidity of air was maintained at $85-90 \%$ and temperature at $16 \pm 1{ }^{\circ} \mathrm{C}$. The cultivation was additionally lit with fluorescent light of $500 \mathrm{~lx}$ intensity for $10 \mathrm{~h}$ a day and aerated in such a way as to maintain $\mathrm{CO}_{2}$ concentration below $800 \mathrm{ppm}$. Fruiting bodies were harvested successively as they matured.

\section{Sample preparation and analysis of Ge and Se}

\section{Sample collection}

Samples were collected, weighed, dried in an electric dryer (SLW 53 STD, Pol-Eko) at $50 \pm 2{ }^{\circ} \mathrm{C}$ for $48 \mathrm{~h}$, weighed again for dry weight determination and then ground for $0.5 \mathrm{~min}$ in a Cutting Boll Mill 200 (Retsch GmbH, Haan, Germany) to obtain powdered samples and finally treated in the extraction procedure.

\section{Extraction procedure}

The extraction procedure was based on the work of Gonzálvez et al. [31], modified for the conditions needed for hyphenated system determination and described previously [32]. $1.000 \pm 0.005 \mathrm{~g}$ of the sample was put into a glass flask containing $10 \mathrm{~mL}$ of $1 \mathrm{~mol} \mathrm{~L}^{-1}$ phosphoric acid and extracted in an ultrasonic bath (30 min at ambient temperature). Next, the solution was filtered using paper filter washed with $200 \mathrm{~mL}$ of water and $20 \mathrm{~mL}$ of phosphoric buffer ( $\mathrm{pH}$ 5.5) or centrifuged. The $\mathrm{pH}$ of the solution was adjusted at $6-6.5$ by the addition of $10 \mathrm{~mol} \mathrm{~L}^{-1}$ solution of sodium hydroxide. Finally, the solution was diluted to $20 \mathrm{~mL}$ by phosphate buffer. The Se species in the acid extracts were determined by HPLC-HG-AAS immediately after the extraction procedure.

\section{Instrumentation}

Hyphenated high-performance liquid chromatography with hydride generation atomic absorption spectrometry detection (HPLC-HG-AAS) systems has been constructed and described in our previous papers [32,33]. The hyphenated analytical system consisted of a Shimadzu liquid chromatograph (LC-10A) equipped with a HPLC pump (LC-10AT), vacuum degasser unit (GT-104), Rheodyne PEEK valve (IDEX, USA) and an anion-exchange column Supelco LCSAX1 $(250 \mathrm{~mm}, 4.6 \mathrm{~mm}$ i.d., resin particle size $5 \mu \mathrm{m})$ thermostated by a column oven (CTO-10ASvp). The chromatographic run was isocratic at $3 \mathrm{~mL} \mathrm{~min}^{-1}$ with an injection volume of $200 \mu \mathrm{L}$. The measurements were performed with a Model SpectraAA 220FS spectrometer (Varian, Australia) with an UltrAA Se hollow cathode lamp.

\section{Analytical procedure}

The selenium species $\mathrm{Se}(\mathrm{VI})$ does not form a volatile hydride, so to get an analytical signal in the HG-AAS system it was necessary to perform a preliminary reduction of $\mathrm{Se}(\mathrm{VI})$ to $\mathrm{Se}(\mathrm{IV})$. The reduction was carried out on-line by heating the sample $\left(90-100{ }^{\circ} \mathrm{C}\right)$ with the reducing agent: $0.5 \mathrm{~mol} \mathrm{~L}^{-1}$ thiourea solution in $10 \mathrm{~mol} \mathrm{~L}^{-1}$ hydrochloric acid. The eluate from the chromatographic column was joined with the stream of the reducing agent (flow rate $1 \mathrm{~mL} \mathrm{~min}^{-1}$ from the peristaltic pump) through a T-shape coupling and directed to the Tygon capillary loop (inner diameter $0.82 \mathrm{~mm}$ ) heated in a water bath. The capillary loop outlet was connected to the hydride generation system. For both analytical systems PEEK transfer tubing of the eluent from the LC column to the hydride generation unit was inserted into a Tygon sleeve. The continuous hydride generation system (VGA-77, Varian) consisted of a manually controlled, peristaltic four-channel pump with Tygon tubing $(0.6 \mathrm{~mm}$ i.d.), one reaction coil (PTFE tubing $0.8 \mathrm{~mm}$ i.d., $75 \mathrm{~cm}$ length) and three-way connectors. The gas-liquid separator was made of glass, and the dead interior volume was $3 \mathrm{~mL}$. For the atomization of the Se hydrides (detected at $196.0 \mathrm{~nm}$ ), a heating controller, electrothermally heating mantle and a quartz tube (ETC-60, Varian) heated to $900{ }^{\circ} \mathrm{C}$ were used. The chromatograms were displayed on the screen of a personal computer using the signal graphics option of the AAS software (Varian), and as a separate print out of the screen. Peak areas or height were calculated by the AAS software.

The number of validation parameters characterising the analytical method were determined. The limits of detection 
$0.01 \mathrm{mg} \mathrm{kg}^{-1}$ of dry matter both for Se(IV) and $\mathrm{Se}(\mathrm{VI})$ and the uncertainty of results (expressed as relative standard deviation, RSD) at the level of $10 \%$ for both selenium forms were obtained. As it was impossible to estimate the measurement traceability because of the lack of any certified reference materials for the determination of $\mathrm{Se}_{\mathrm{in}}$ species, the recovery of each Se species was measured upon addition of a standard to the sample. A recovery of $96-105 \%$ of each species was satisfactory.

\section{Total selenium determination}

Total selenium concentration $\left(\mathrm{Se}_{\text {total }}\right)$ was measured with the use of the inductively coupled plasma optical emission spectrometer Agilent 5110 ICP-OES (Agilent, USA). The standard conditions were used: Radio Frequency (RF) power $1.2 \mathrm{~kW}$, nebulizer gas flow $0.7 \mathrm{~L} \mathrm{~min}^{-1}$, auxiliary gas flow $1.0 \mathrm{~L} \mathrm{~min}^{-1}$, plasma gas flow $12.0 \mathrm{~L} \mathrm{~min}{ }^{-1}$, Charge Coupled Device (CCD) temperature $-40{ }^{\circ} \mathrm{C}$, axial plasma view, accusation time $5 \mathrm{~s}, 3$ replicates. The analytical wavelengths were 196.026 and $209.426 \mathrm{~nm}$ for Se and Ge, respectively. The limit of detection $0.01 \mathrm{mg} \mathrm{kg}^{-1}$ of dry matter for Se and $0.04 \mathrm{mg} \mathrm{kg}^{-1}$ of dry matter for Ge with the uncertainty of results (measured as RSD) at the level of 5.0\% were obtained. Traceability was measured with the standard addition procedure. The concentration of the organic selenium $\left(\mathrm{Se}_{\text {org }}\right)$ was calculated as the difference between total selenium concentration $\left(\mathrm{Se}_{\text {total }}\right)$ and the concentration of inorganic selenium $\left(\mathrm{Se}_{\mathrm{in}}\right.$ ) compounds [a sum of $\mathrm{Se}$ (IV) and $\mathrm{Se}(\mathrm{VI})]$.

\section{Gases and reagents}

Compressed argon gas of N-50 purity (99.999\%) obtained from Linde (Poland) was employed as the carrier gas for Se vapour to the quartz cell without further purification. Water was redistilled and further purified with the water purification system Milli-Q (Millipore, USA). Standard selenium solutions ( $1000 \mathrm{mg} \mathrm{Se} \mathrm{L}^{-1}$ ) were prepared by dissolving appropriate amounts of sodium selenite $\left(\mathrm{Na}_{2} \mathrm{SeO}_{3}\right)$, sodium selenate $\left(\mathrm{Na}_{2} \mathrm{SeO}_{4}\right)$ and selenomethionine, obtained from Sigma-Aldrich (USA). Commercial selenium standard (Romil, England) was used for total selenium and germanium determination. The standard stock solutions were stored in glass bottles at $4{ }^{\circ} \mathrm{C}$ in darkness. Low concentration standards obtained by dilution of the stock solutions were prepared daily. Sodium tetrahydroborate(III), used as reducing solution $(3 \% \mathrm{w} / \mathrm{w})$, was prepared daily by dissolving $\mathrm{NaBH}_{4}$ (Merck) in high-purity water, stabilised with $1 \%$ (w/w) $\mathrm{NaOH}$ (Merck) solution to decrease its rate of decomposition. The solution was used without filtration. The $\mathrm{HCl}$ solution was of the highest quality grade (Suprapure, Merck). Thiourea of the analytical quality grade was obtained from
Merck. The buffered mobile phase was prepared by mixing disodium hydrophosphate $\left(\mathrm{Na}_{2} \mathrm{HPO}_{4}\right) 100 \mathrm{mmol} \mathrm{L}^{-1}$ with potassium dihydrophosphate $\left(\mathrm{KH}_{2} \mathrm{PO}_{4} \cdot 2 \mathrm{H}_{2} \mathrm{O}\right) 10 \mathrm{mmol} \mathrm{L}^{-1}$ obtained from Merck.

\section{Determination of ergosterol}

Ergosterol extraction and determination were carried out according to Perkowski et al. [34]. Briefly, about a hundred milligrams of powdered mushroom samples were mixed with pure methanol and $\mathrm{NaOH}$. After irradiation twice in a microwave oven and cooling, $\mathrm{HCl}$ was added. The extraction was repeated three times. The mixed extracts were dried under a nitrogen atmosphere, redissolved in $1 \mathrm{~mL}$ of pure methanol, and filtered through syringe filters (Fluoropore Membrane Filters). The determination of ergosterol was performed on an ACQUITY UPLC H-Class System with a PDA e $\lambda$ Detector (Waters Corporation, Milford, MA, USA) and an Acquity UPLC HSS T3 $\mathrm{C}_{18}$ column $(150 \mathrm{~mm} \times 2.1 \mathrm{~mm}$, particle size $1.8 \mu \mathrm{m}$ ), (Waters, Ireland). Isocratic elution with a mobile phase consisting of methanol (85\%), acetonitrile $(10 \%)$ and water $(5 \%)$ was carried out with a flow of $0.5 \mathrm{~mL} \mathrm{~min}^{-1}$.

\section{Statistical analysis}

The results are presented as mean values from triplicates and the standard deviation calculated by STATISTICA 12 software (StatSoft, USA). The differences in ergosterol content were analysed with one-way analysis of variance (ANOVA) followed by the post hoc Tukey's test $(P<0.05)$.

The bioaccessibility (\%) of Ge and Se in the various experimental models applied in the present study was calculated using the formula: $x=\frac{\text { content in fruiting bodies }}{\text { initial substrate content }} \times 100$.

\section{Results}

\section{Characteristics of biomass of fruiting bodies}

The biomass of both G. lucidum and P. ostreatus from the substrates enriched with only Se was not related to any important changes in the morphology of these mushroom species (Figs. 1, 2). Similar observations for mushrooms growing in the substrate enriched with Ge were recorded, except for G. lucidum fruiting bodies (lower size) treated with the highest addition of the metalloid. The combined exposure of G. lucidum to Ge and Se caused significant changes in the morphology (lower size than in the control and changes in colour) of their fruiting bodies growing under systems $\mathrm{S}_{2}$ and $\mathrm{S}_{3}$. Similar results were also observed for $P$. ostreatus for the two highest concentrations of both Se forms and $\mathrm{Ge}$ additions. Fruiting bodies growing under $\mathrm{S}_{2}$ were 

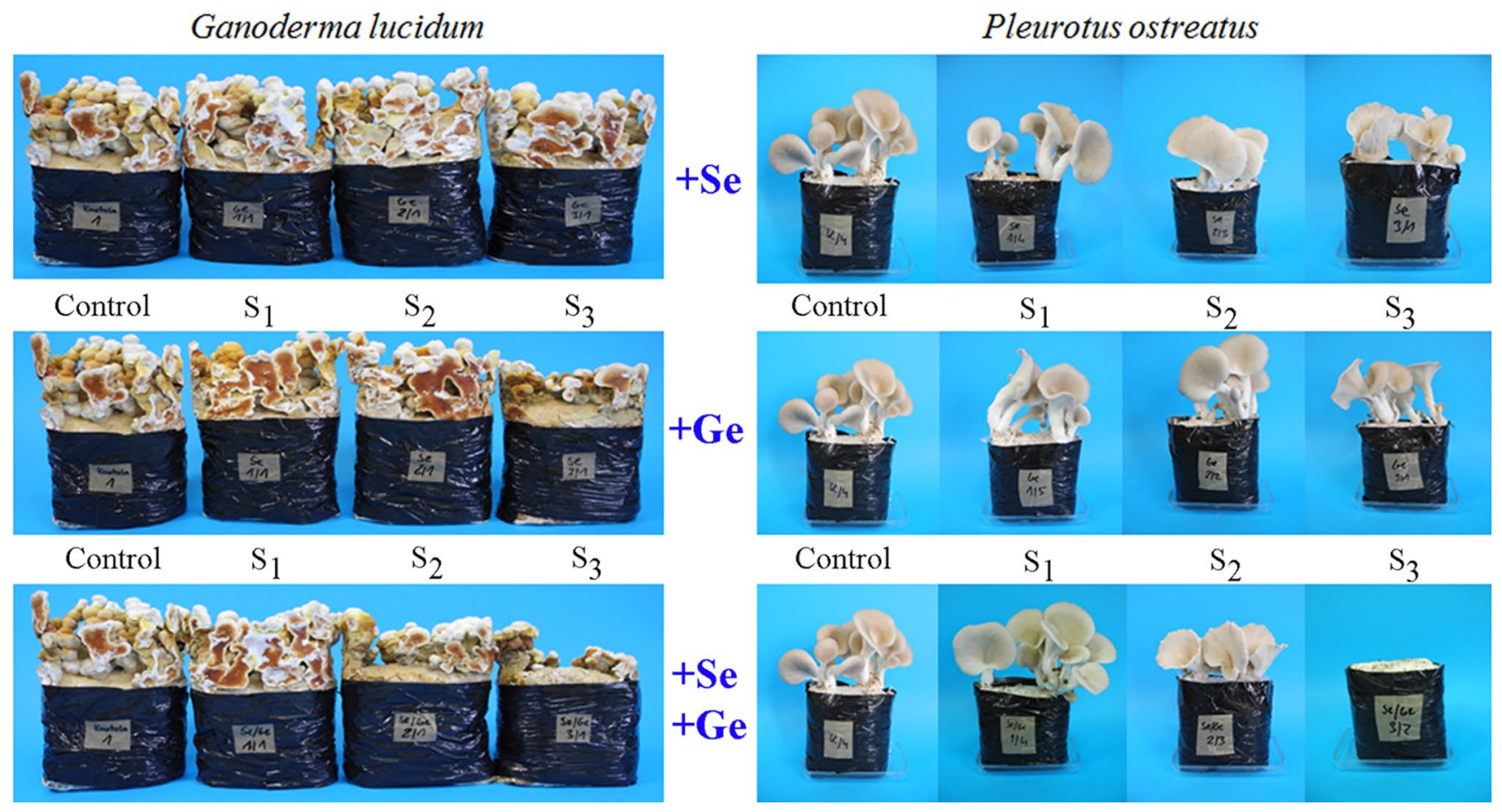

Fig. 1 Morphology of Ganoderma lucidum and Pleurotus ostreatus fruiting bodies growing under particular experimental systems

whiter (not visible in Fig. 1) and characterised by a lower size than the control, while G. lucidum growing under $\mathrm{S}_{3}$ was not able to yield.

The biomass of three independent controls of G. lucidum was in the range $72.7-74.1 \mathrm{~g}$ per $400 \mathrm{~g}$ of substrate, while for $P$. ostreatus it was $81.3-81.9 \mathrm{~g}$, which indicated stable conditions of growth (Fig. 2). Addition of $\mathrm{Se}, \mathrm{Ge}$ or $\mathrm{Ge}+\mathrm{Se}$ to the substrate of G. lucidum, did not cause any significant decrease in the biomass of this mushroom $(89.2 ; 86.2$ and $70.3 \%$ of control for systems enriched with $\mathrm{Se}, \mathrm{Ge}$ and $\mathrm{Ge}+\mathrm{Se}$ ), respectively. A similar result was observed for $P$. ostreatus growing in substrates supplemented with Se only (85.1\% of control).

The exposure of $P$. ostreatus to Ge in its highest concentration $\left(\mathrm{S}_{3}\right)$ caused a significant decrease of biomass $(59 \%$ of control). The biomass of $P$. ostreatus exposed to $\mathrm{Se}+\mathrm{Ge}$ in system $\mathrm{S}_{2}$ was significantly lower than for the control and $\mathrm{S}_{1}$ (72.6\% of control), which suggested that P. ostreatus is more sensitive to $\mathrm{Ge}+\mathrm{Se}$ addition than G. lucidum.

\section{Content of Ge and Se in fruiting bodies}

The content of $\mathrm{Ge}$ in G. lucidum increased with the increase of the metalloid concentration in the substrate (Fig. 3a). Addition of Se stimulated the accumulation of $\mathrm{Ge}$ in systems $\mathrm{S}_{2}$ and $\mathrm{S}_{3}$, where the content of $\mathrm{Ge}$ in mushrooms supplemented with two elements was significantly higher than under the supplementation with only Ge
(64.5 and $113 \%$, respectively). A different tendency was observed for P. ostreatus fruiting bodies (Fig. 3c). Cultivation of this species in the substrate with $\mathrm{Se}$ or $\mathrm{Ge}+\mathrm{Se}$ did not cause any significantly higher/lower accumulation of Ge.

Selenium content in G. lucidum fruiting bodies increased with the increase of the element in the substrate with the same significant differences as observed for $\mathrm{Ge}$ (Fig. 3b). Significantly higher contents of Se were found in fruiting bodies growing under $\mathrm{S}_{2}$ and $\mathrm{S}_{3}$ systems enriched with $\mathrm{Ge}+\mathrm{Se}$ than in those supplemented with Ge only (by 132 and $37.6 \%$, respectively). The content of Se in $P$. ostreatus increased with the increase of the metalloid in the substrate but as for Ge in G. lucidum; there were no significant differences in Se content in fruiting bodies cultivated in both kinds of substrates (enriched with one or two metalloids).

As shown in Table 1, the bioaccessibility of Ge was generally low, although higher in P. ostreatus. In G. luci$d u m$ it increased with increasing initial Ge content. The simultaneous addition of Se to the substrate resulted in increased accumulation of Ge in G. lucidum fruiting bodies, particularly at higher initial content. A similar observation was made for $\mathrm{Se}$ in both species-the simultaneous presence of Ge increased the content of Se in fruiting bodies. Higher bioaccessibility of Se was noted for $P$. ostreatus. 

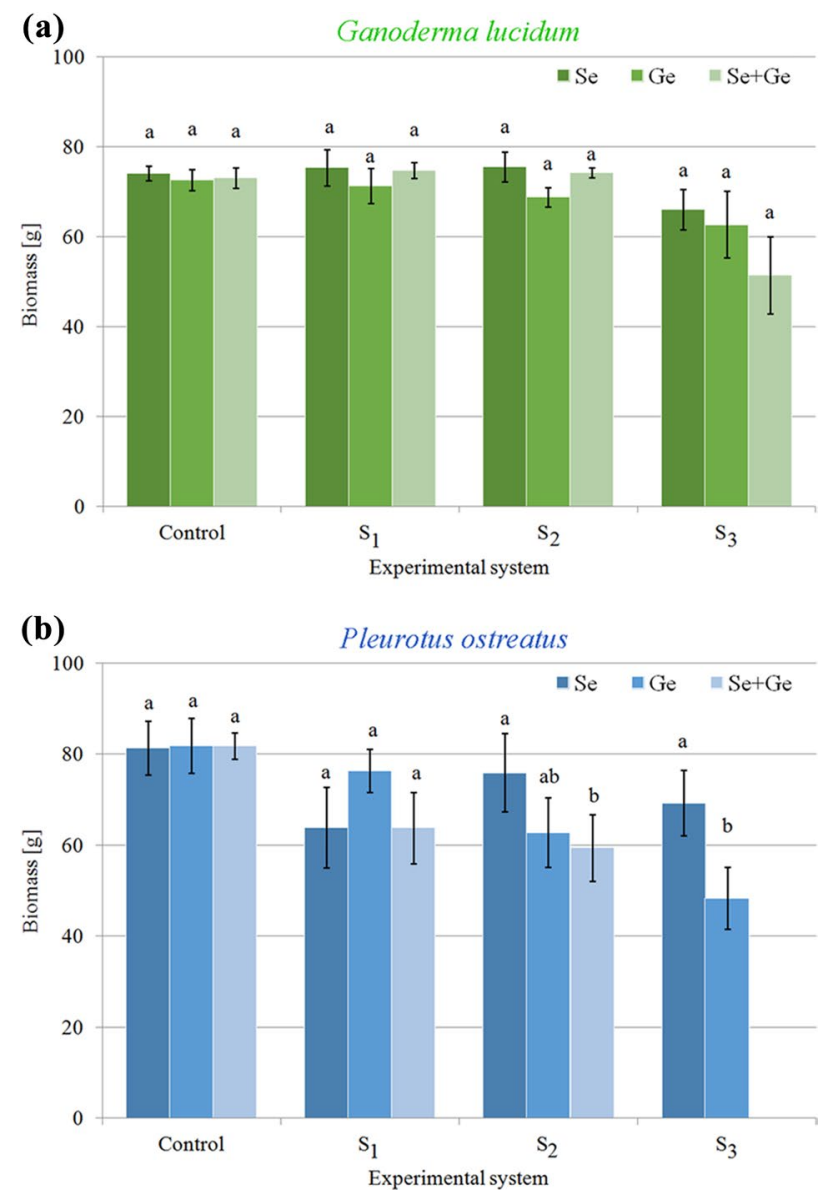

Fig. 2 Biomass (g) of Ganoderma lucidum (a) and Pleurotus ostreatus (b) fruiting bodies

\section{Content of Se species in fruiting bodies}

Accumulation of Se added to the substrate as Se(IV) and $\mathrm{Se}(\mathrm{VI})$ in the same concentrations resulted in different concentrations of these forms in fruiting bodies (Fig. 4). Despite the addition of inorganic Se forms to the substrate, the dominant form in both mushroom species and all four experimental systems was $\mathrm{Se}_{\text {org }}$. The proportion of $\mathrm{Se}_{\text {org }}$ in G. lucidum growing in the substrate enriched with Se only (Fig. 4a) increased from $62.7 \%\left(\mathrm{~S}_{1}\right)$ to $87.1 \%\left(\mathrm{~S}_{3}\right)$ of total $\mathrm{Se}$ content. The addition of $\mathrm{Ge}$ and Se to the substrate caused a higher increase of $\mathrm{Se}_{\text {org }}$ participation [from $56.0 \%\left(\mathrm{~S}_{1}\right)$ to $91.6 \%\left(\mathrm{~S}_{3}\right]$ in the total content of the metalloid. It is worth underlining that cultivation of G. lucidum in substrates with different additions $\left(\mathrm{S}_{1}-\mathrm{S}_{3}\right)$ of the same concentration of both Se forms was related to the similar ratio of their contents (1.7; 0.7 and 2.0 for $S_{1}, S_{2}$ and $S_{3}$, respectively) in fruiting bodies. The addition of Ge to the substrate did not change this ratio for mushrooms growing under $S_{1}$ and $S_{2}$ systems (1.6 and 1.4, respectively), while for $S_{3}$ the ratio was 5 . This could suggest that the presence of Ge in higher concentration could improve $\mathrm{Se}_{\text {org }}$ accumulation by G. lucidum fruiting bodies.

The accumulation of Se forms in $P$. ostreatus fruiting bodies was diverse with the highest proportion in fruiting bodies growing in the substrate with Se addition only [from $70.7 \%\left(\mathrm{~S}_{3}\right)$ to $82.7 \%\left(\mathrm{~S}_{2}\right.$ ] of total Se content (Fig. $\left.4 \mathrm{c}\right)$ but also with $\mathrm{Ge}$ and Se addition jointly [from $75.7 \%\left(\mathrm{~S}_{1}\right)$ to $77.6 \%\left(\mathrm{~S}_{2}\right)$ of total Se content], (Fig. $4 \mathrm{~d}$ ). The ratio of $\mathrm{Se}(\mathrm{IV}) / \mathrm{Se}(\mathrm{VI})$ in mushrooms growing in substrates enriched with only Se was similar for systems $S_{1}$ and $S_{3}$ (3.3 and 3.1, respectively) and lower for $S_{2}$ (1.4). Addition of Ge to the substrate did not cause the ratio of both Se forms to be 4.1 and 3.9, respectively, for $S_{1}$ and $S_{2}$ systems.

\section{Content of ergosterol}

Ergosterol contents were $325-337$ and $180-186 \mathrm{mg} \mathrm{kg}^{-1}$ $\mathrm{dm}$ in G. lucidum and P. ostreatus, respectively, within the triplicate control variant (Fig. 5). Only the addition of Se for G. lucidum in the experimental system $\mathrm{S}_{1}$ resulted in an elevation of ergosterol content $\left(367 \mathrm{mg} \mathrm{kg}^{-1} \mathrm{dm}\right)$ in comparison to the control. In all the experimental systems, high content of ergosterol was observed only if $\mathrm{Se}$ was added $\left(\mathrm{S}_{1}\right.$, $\mathrm{S}_{2}$, and $\mathrm{S}_{3}$ ).

Supplementation with Ge resulted in a significant drop of ergosterol to $77.2 \mathrm{mg} \mathrm{kg}^{-1} \mathrm{dm}$ in $\mathrm{S}_{3}$. Supplementation of $G$. lucidum with combined $\mathrm{Se}$ and $\mathrm{Ge}$ lead to a further reduction of the content, although in comparison to Ge supplementation the decrease was significant only for $\mathrm{S}_{1}$. Fruiting bodies of $P$. ostreatus in all experimental systems contained lower ergosterol content in comparison to the control. In experimental systems $S_{1}$ and $S_{2}$ the highest ergosterol content was observed for Se supplementation, whereas the addition of $\mathrm{Ge}$ caused a decrease of ergosterol level. The Se and Ge addition resulted in a decrease in ergosterol content. However, significant changes in ergosterol content between Ge and $\mathrm{Se}+\mathrm{Ge}$ supplementation were confirmed only in $\mathrm{S}_{1}$. In the experimental system $\mathrm{S}_{3}$, a similar content of ergosterol was determined for both Se and Ge additions.

\section{Discussion}

This is the first study to demonstrate the potential effects of $\mathrm{Ge}$, alone or in combination with $\mathrm{Se}$, on the morphology, growth and chemical constituents of mushroom fruiting bodies. Moreover, information on Ge uptake and accumulation in mushrooms has been limited, thus this study adds to a general understanding of the effects of this metalloid in biological systems. In fact, its content in various foodstuffs has also been rarely assessed and has mostly concerned vegetables and fruits [35]. The highest levels of $\mathrm{Ge}$ in commercially available mushrooms were noted 


\section{Ganoderma lucidum}
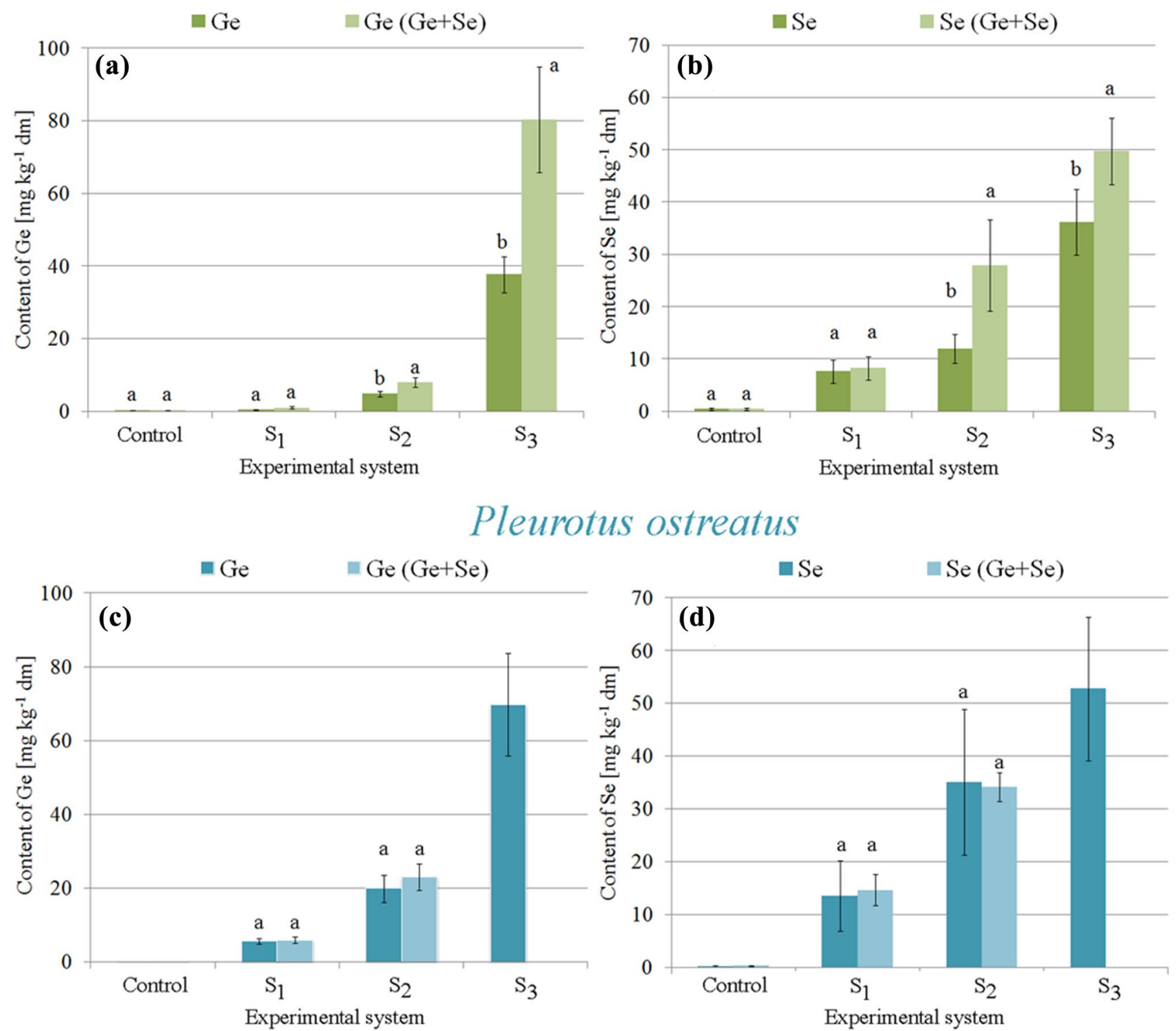

Fig. 3 Content $\left(\mathrm{mg} \mathrm{kg}^{-1} \mathrm{dm}\right)$ of Ge and Se in Ganoderma lucidum (a, b) and Pleurotus ostreatus (c, $\left.\mathbf{d}\right)$ fruiting bodies

so far for selected Ganoderma species in which it could exceed $1 \mathrm{mg} \mathrm{kg}^{-1}$, while specifically in G. lucidum, which was also tested in the present study, it reached approx $0.5 \mathrm{mg} \mathrm{kg}^{-1}[19,23]$. The present study experimentally suggests that this may result from substrate contamination with $\mathrm{Ge}$, particularly if one considers that Ge bioaccessibility for G. lucidum was rather low. However, at low doses, Ge has been experimentally reported to exert potentially positive effects through antioxidant, antimutagenic, and antitumor activities [36], although it should be highlighted that there is no clear evidence for any healthbeneficial effects of dietary $\mathrm{Ge}$, and in certain forms, it may be toxic for humans [37]. Overall, the increased Ge content in commercially cultivated Ganoderma sp. and the reasons behind it require further studies to ensure consumer safety.

Although contamination with Ge does not currently represent a major ecological problem, its use in numerous electronic applications, as well as its emission from some combustion processes, suggest that its levels in the surrounding environment will slowly increase [22]. Considering that mushrooms can accumulate various elements from the ambient environment it is important to ascertain to what extent this element can be present in fruiting bodies, whether this can affect mushroom growth and chemistry, and last but not least, whether it can interfere with other 
Table 1 The bioaccessibility of Ge and Se for fruiting bodies $P$. ostreatus and G. lucidum in various experimental models

\begin{tabular}{lllc}
\hline Element & Experimental model & \multicolumn{2}{c}{ Bioavailability $(\%)$} \\
\cline { 3 - 4 } & & $\begin{array}{l}\text { Pleurotus } \\
\text { ostreatus }\end{array}$ & $\begin{array}{c}\text { Gano- } \\
\text { derma } \\
\text { lucidum }\end{array}$ \\
\hline $\mathrm{Ge}$ & & 0.4 \\
& $\mathrm{~S} 1: \mathrm{Ge}$ & 5.4 & 0.9 \\
& $\mathrm{~S} 1: \mathrm{Se}+\mathrm{Ge}$ & 5.6 & 0.9 \\
& $\mathrm{~S} 2: \mathrm{Ge}$ & 3.9 & 1.5 \\
& $\mathrm{~S} 2: \mathrm{Se}+\mathrm{Ge}$ & 4.3 & 3.5 \\
& $\mathrm{~S} 3: \mathrm{Ge}$ & 6.6 & 7.6 \\
$\mathrm{Se}$ & $\mathrm{S}: \mathrm{Se}+\mathrm{Ge}$ & - & 23.6 \\
& $\mathrm{~S} 1: \mathrm{Se}$ & 41.8 & 25.3 \\
& $\mathrm{~S} 1: \mathrm{Se}+\mathrm{Ge}$ & 45.3 & 9.2 \\
$\mathrm{~S} 2: \mathrm{Se}$ & 27.0 & 21.5 \\
& $\mathrm{~S} 2: \mathrm{Se}+\mathrm{Ge}$ & 26.4 & 14.1 \\
& $\mathrm{~S} 3: \mathrm{Se}$ & 20.3 & 19.2 \\
\hline $\mathrm{S} 3: \mathrm{Se}+\mathrm{Ge}$ & - &
\end{tabular}

elements in the substrate such as Se whose use in mushroom biofortification has been discussed in some previous research $[9-11,25,26]$.

While Se is a vital element, Ge is a non-essential one that may display certain biological activities but with no known physiological function. As previously shown in G. lucidum, the presence of $\mathrm{Se}$ in a growing medium can induce toxic effects in G. lucidum mycelia while $\mathrm{Ge}$, which is easily taken up and accumulated in fruiting bodies, did not induce any detectable effects in the $10-1200 \mathrm{mg} \mathrm{kg}^{-1}$ range [38]. In line with these findings, the present study also highlights that Ge did not significantly alter the biomass and growth of this species except for a slight decrease in yield when it was present in the substrate along with Se at the highest level. It also induced some morphological changes under the highest levels. More profound effects were observed in P. ostreatus in which lower biomass was produced after Ge presence in the substrate, but this effect appeared to be further magnified by the presence of Se. Notably, however, no effects were noted up to $5 \mathrm{mM}$ of Ge. The difference in the effect of Ge alone or combined with Se on the growth of $P$. ostreatus and G. lucidum is most likely due to the higher bioaccessibility of Ge to the former. Altogether, these observations indicate that although Ge is taken up by mycelia and accumulated in the fruiting bodies of both species, it does not induce any acute toxic effects at levels that could potentially be expected in commercial unaltered substrates. The present study also indicates that mushrooms are likely to be more resistant to Ge presence than plant crops such as wheat and barley, in which toxic effects such as organ necrosis, are already observed in the $\mu \mathrm{M}$ range $[39,40]$. A full understanding of the potential mechanisms behind this tolerance, despite an accumulation of $\mathrm{Ge}$ in mushrooms and its translocation to fruiting bodies, would require further studies.

The ability of the studied mushrooms to grow and accumulate $\mathrm{Ge}$ in their fruiting bodies may have some potentially interesting industrial applications in its recycling [21, $22]$. Due to the commercial value of $\mathrm{Ge}$, its re-processing is economically justified. It is known that tailings, e.g. those originating from zinc mining, can be characterized by increased levels of Ge [41]. Some mushroom species have already been shown to maintain their growth on highly contaminated soils polluted with flotation tailings [42]. Thus, the observation of the present study represents a promising possibility for the potential use of mushrooms to recycle Ge. This would require further more detailed experimental and in-field studies coupled with the development of methods to extract $\mathrm{Ge}$ from fruiting bodies, although some approaches in this respect have already been suggested for plant biomass [43].

As recently demonstrated by Goy et al. [44] using scanning electron microscopy, high concentrations of Se in the ambient environment can also lead to various ultrastructural alterations in mushrooms, such as a decrease in hyphal diameter and changes in spore number and shape. As previously established, when Se is added to a substrate at $0.4 \mu \mathrm{M}$, it is incorporated into the fruiting bodies without any significant reduction in growth and yielded biomass [25]. As shown in the present study, Se supplemented in inorganic forms was transformed and determined in fruiting bodies in organic selenocompounds. Similar transformations were previously observed by Rzymski et al. [26] in Agaricus bisporus and Rathore et al. [45] in Calocybe indica. This is an important finding if one considers that the biological role of Se is mainly mediated by its organic form, particularly selenoproteins with selenocysteine at their active centre [46]. This also concerns the human organism in which Se is an essential element of important metabolic pathways, including thyroid hormone metabolism, antioxidant defence systems and regulation of immune function [47-49]. The addition of Se in the overgrown substrate may potentially increase the biological activity of polysaccharides and proteins isolated from $G$. lucidum [50, 51]. In turn, biofortification of $P$. ostreatus with Se was found to increase the protein content and antioxidant properties of the mushrooms [13, 52].

As shown in the present study, Se and Ge were taken up and accumulated in fruiting bodies in a concentrationdependent manner. Supplementation with both elements resulted in decreased ergosterol content in the fruiting bodies of G. lucidum and P. ostreatus. This effect was, however, much more evident for Ge. Ergosterol is a vitamin D precursor as it can be transformed under UV radiation in a biologically active form of $\mathrm{D}_{2}$ - ergocalciferol [53-55]. Although it appears that ergocalciferol has a lower biological effect in humans than cholecalciferol, it may be an important 
Ganoderna lucidum
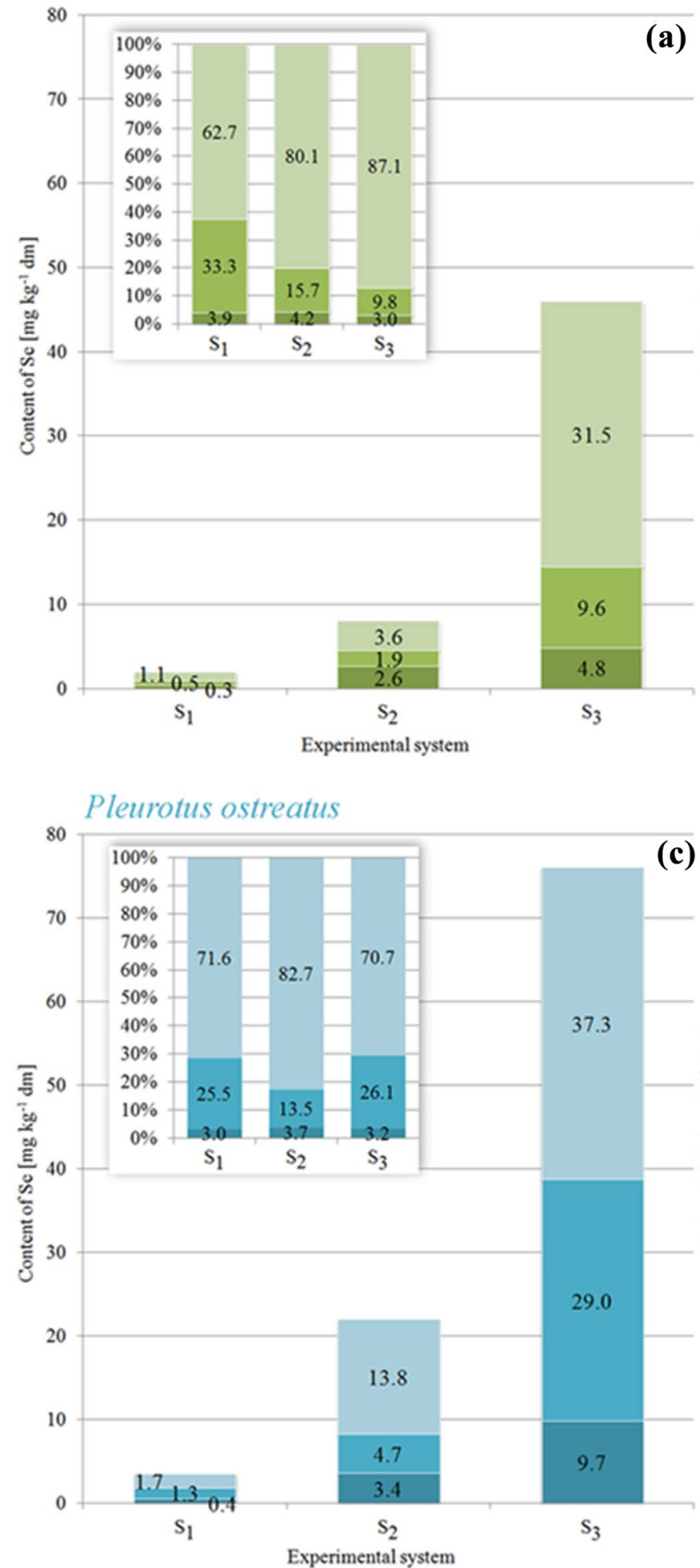
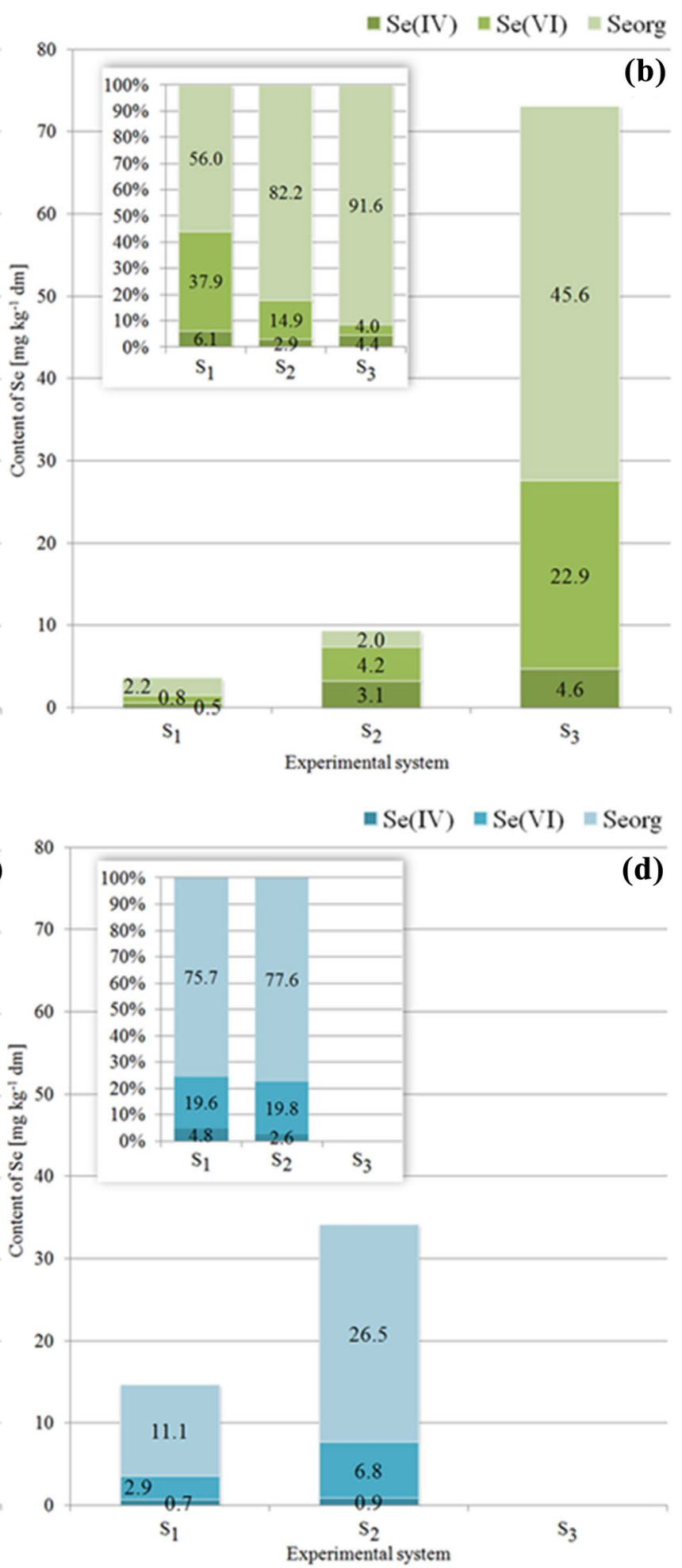

Fig. 4 Content $\left(\mathrm{mg} \mathrm{kg}^{-1} \mathrm{dm}\right)$ of Se forms in Ganoderma lucidum (a, b) and Pleurotus ostreatus (c, d) fruiting bodies growing in substrates enriched with $\mathrm{Se}(\mathbf{a}, \mathbf{c})$ and $\mathrm{Se}+\mathrm{Ge}(\mathbf{b}, \mathbf{d})$ with percentage participation of particular Se forms in total content of $\mathrm{Se}$

source for certain diet groups such as vegans and vegetarians [56]. Therefore, it appears that Ge can directly or indirectly alter sterol synthesis in mushrooms, an effect previously established for various antifungal agents. Considering the pivotal role of ergosterol for membrane fluidity and structure [57], the contamination of mushrooms with Ge can result 

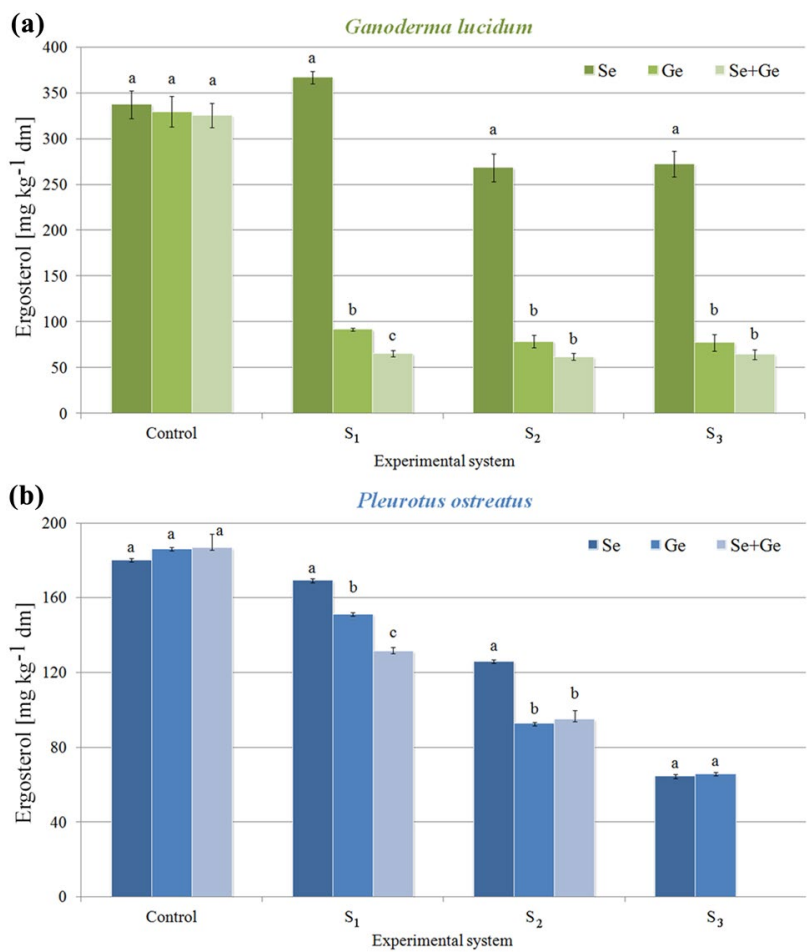

Fig. 5 Content $\left(\mathrm{mg} \mathrm{kg}^{-1} \mathrm{dm}\right)$ of ergosterol Ganoderma lucidum and Pleurotus ostreatus growing in substrates enriched with $\mathrm{Se}, \mathrm{Ge}$ and $\mathrm{Se}+\mathrm{Ge}$

in unappreciated consequences for their growth and physiology. To the best of our knowledge, this is the first time that such effects of Ge have been observed. Further studies would be required to fully elucidate the mechanism(s) of $\mathrm{Ge}$ toxicity in mushrooms and whether its impact on ergosterol content represents a cause or effect.

Even though some studies using in vivo experiments have indicated that certain forms of Ge (e.g. b[beta]bis(carboxyethyl) germanium sesquioxide, known as Ge-132) can have potentially beneficial immunomodulatory effects [58] one should bear in mind that cases of human poisonings, some of which resulted in renal failure and a fatal outcome, associated with Ge intake (including Ge-132 supplements) have also been documented in the literature [37, 59]. Prolonged in vivo exposures to Ge resulted in impaired function of liver and kidney, and myopathy in rodents [60, 61]. The present study shows that Ge can be effectively accumulated if present in the substrate at high levels. Its content, reaching $80 \mathrm{mg} \mathrm{kg}^{-1}$ and exceeding $60 \mathrm{mg} \mathrm{kg}^{-1}$, was observed in G. lucidum and P. ostreatus, respectively. These levels are much higher than usually noted for foodstuffs [35]. Nevertheless, one should note that our study only assessed the total element content. The forms in which Ge can be present in mushrooms remain to be explored. It is plausible that it may form compounds with Se such as Ge selenide [62], although it is unknown whether such a phenomenon occurs in mushrooms if high levels of Se and Ge are simultaneously available. The bioavailability of Ge in mushrooms, similar to other food products, is also unexplored. It has been shown in vivo in rabbits that Ge oxides are characterized by low oral bioavailability $(<10 \%)$, and even lower values were noted for organic compounds [63].

It should be remembered that the present study has an experimental nature and does not suggest that commercially produced mushrooms may be contaminated with Ge. In fact, recent analyses indicate that $\mathrm{Ge}$ is undetectable in various cultivated mushrooms such as Agaricus bisporus, Amauroderma rude, Auricularia auricula-judae, Auricularia nigricans, Ganoderma lucidum, Lentinula edodes, Lignosus rhinocerus, Ophiocordyceps sinensis, Pleurotus ostreatus, Sparassis crispa, Tremella fuciformis, Wolfiporia cocos, Volvariella volvacea and Pleurotus sp. [14, 19]. Finally, despite anecdotal claims that consumption of mushrooms containing a high content of Ge may alleviate health concerns, there is no experimental or clinical evidence of such properties, and the present study cannot be used to support them.

\section{Conclusions}

Little attention has so far been given to studies of the interaction between $\mathrm{Ge}$ and Se. Therefore, the obtained results indicate the need for such studies in the future. The proper intake of Se in a balanced human diet plays a significant role. Thus, the possible presence of increased Ge concentration in the substrate can be related to a significantly higher content of Se in mushroom fruit. Visible symptoms such as changes in size or colour of mushroom bodies will be present, but a clear synergistic effect during exposure to higher concentrations of $\mathrm{Ge}$ in the substrate may be related with a negative influence on humans through the toxicity of both elements. The studied mushroom species were grown in substrate enriched with inorganic Se salts only and the dominant forms in G. lucidum were organic Se compounds. This tendency strengthened with increased concentration of Ge in the substrate, thereby illustrating the significant role of Ge compounds in the accumulation of Se in G. lucidum, which was not the case for P. ostreatus. Additionally, cosupplementation of the substrate with Ge or cultivation of mushrooms with $\mathrm{Ge}$ only resulted in a reduction of ergosterol content, which highlights the significance of the interaction between these elements. Due to the important role of ergosterol in fungi the presence in the substrate of some metalloids, especially Ge, may have a negative impact on the growth and physiology of the fungus. 
Funding This study was funded by the Polish Ministry of Science and Higher Education programme "Regional Initiative of Excellence" in years 2019-2022 (grant number 005/RID/2018/19).

\section{Compliance with ethical standards}

Conflict of interest The authors declare that they have no conflict of interest.

Compliance with ethics requirements This article does not contain any research involving human participants or animals performed by any of the authors.

Open Access This article is distributed under the terms of the Creative Commons Attribution 4.0 International License (http://creativeco mmons.org/licenses/by/4.0/), which permits unrestricted use, distribution, and reproduction in any medium, provided you give appropriate credit to the original author(s) and the source, provide a link to the Creative Commons license, and indicate if changes were made.

\section{References}

1. Kalač $P$ (2013) A review of chemical composition and nutritional value of wild-growing and cultivated mushrooms. J Sci Food Agric 93:209-2018

2. Bianchi I (2017) Medicinal mushrooms. In: Fioranelli M (ed) Integrative cardiology. Springer, Cham

3. Figueiredo L, Régis WCB (2017) Medicinal mushrooms in adjuvant cancer therapies: an approach to anticancer effects and presumed mechanisms of action. Nutrire 42:28

4. Matute RG, Serra A, Figlas D, Curvetto N (2011) Copper and zinc bioaccumulation and bioavailability of Ganoderma lucidum. J Med Food 14:1273-1279

5. Ogidi OC, Nunes MD, Oyetayo VO, Akinyele BJ, Kasuya MCM (2016) Mycelial growth, biomass production and iron uptake by mushrooms of Pleurotus species cultivated on Urochloa decumbens (Stapf) RD Webster. J Food Res 5:13

6. de Assunção LS, da Luz JMR, da Silva MDCS, Vieira PAF, Bazzolli DMS, Vanetti MCD, Kasuya MCM (2012) Enrichment of mushrooms: an interesting strategy for the acquisition of lithium. Food Chem 134:1123-1127

7. Mleczek M, Siwulski M, Rzymski P, Budzyńska S, Gąsecka M, Kalač P, Niedzielski P (2017) Cultivation of mushrooms for production of food biofortified with lithium. Eur Food Res Technol 243:1097-1104

8. Lee CY, Park JE, Kim BB, Kim SM, Ro HS (2009) Determination of mineral components in the cultivation substrates of edible mushrooms and their uptake into fruiting bodies. Mycobiology 37:109-113

9. Maseko T, Callahan DL, Dunshea FR, Doronila A, Kolev SD, $\mathrm{Ng} \mathrm{K} \mathrm{(2013)} \mathrm{Chemical} \mathrm{characterisation} \mathrm{and} \mathrm{speciation} \mathrm{of} \mathrm{organic}$ selenium in cultivated selenium-enriched Agaricus bisporus. Food Chem 141:3681-3687

10. Niedzielski P, Mleczek M, Siwulski M, Rzymski P, Gąsecka M, Kozak L (2015) Supplementation of cultivated mushroom species with selenium: bioaccumulation and speciation study. Eur Food Res Technol 241:419-426

11. Yan H, Chang H (2012) Antioxidant and antitumor activities of selenium- and zinc-enriched oyster mushroom in mice. Biol Trace Elem Res 150:236-241
12. Du M, Wang C, Hu XC, Zhao G (2008) Positive effect of selenium on the immune regulation activity of lingzhi or reishi medicinal mushroom, Ganoderma lucidum (W. Curt.: Fr.) P. Karst. (Aphyllophoromycetideae), proteins in vitro. Int $\mathrm{J}$ Med Mushrooms 10:337-344

13. Poniedziałek B, Mleczek M, Niedzielski P, Siwulski M, Gąsecka M, Kozak L, Komosa A, Rzymski P (2017) Bio-enriched Pleurotus mushrooms for deficiency control and improved antioxidative protection of human platelets? Eur Food Res Technol 243:2187-2198

14. Siwulski M, Mleczek M, Rzymski P, Budka A, Jasińska A, Niedzielski P, Kalač P, Gąsecka M, Budzyńska S, Mikołajczak P (2017) Screening the multi-element content of Pleurotus mushroom species using inductively coupled plasma optical emission spectrometer (ICP-OES). Food Anal Methods 10:487-496

15. Mleczek M, Niedzielski P, Siwulski M, Rzymski P, Gąsecka M, Goliński P, Kozak L, Kozubik T (2016) Importance of low substrate arsenic content in mushroom cultivation and safety of final food product. Eur Food Res Technol 242:355-362

16. Rzymski P, Mleczek M, Siwulski M, Gąsecka M, Niedzielski P (2016) The risk of high mercury accumulation in edible mushrooms cultivated on contaminated substrates. J Food Comp Anal 51:55-60

17. Rzymski P, Mleczek M, Siwulski M, Jasińska A, Budka A, Niedzielski P, Kalac P, Gąsecka M, Budzyńska S (2017) Multielemental analysis of fruit bodies of three cultivated commercial Agaricus species. J Food Compos Anal 59:170-178

18. Chenghom O, Suksringram J, Morakot N (2010) Mineral composition and Germanium contents in some Phellinus mushrooms in the Northeast of Thailand. Curr Res Chem 2:24-34

19. Siwulski M, Rzymski P, Niedzielski P, Budka A, Gąsecka M, Kalač P, Jasińska A, Budzyńska S, Kozak L, Mleczek M (2017) Comparison of multielemental composition of Polish and Chinese mushrooms (Ganoderma spp.). Eur Food Res Technol 243:1555-1566

20. Li L, Ruan T, Lyu Y, Wu B (2017) Advances in effect of germanium or germanium compounds on animals - a review. J Biosci Med 5:56-73

21. Moskalyk RR (2004) Review of germanium processing worldwide. Miner Eng 17:393-402

22. Rosenberg E (2009) Germanium: environmental occurrence, importance and speciation. Rev Environ Sci Biotechnol 8:29-57

23. Chiu SW, Wang ZM, Leung TM, Moore D (2000) Nutritional value of Ganoderma extract and assessment of its genotoxicity and antigenotoxicity using comet assays of mouse lymphocytes. Food Chem Toxicol 38:173-178

24. Krystek P, Ritsema R (2004) Analytical product study of germanium-containing medicine by different ICP-MS applications. J Trace Elem Med Biol 18:9-16

25. Rzymski P, Mleczek M, Niedzielski P, Siwulski M, Gąsecka M (2016) Potential of cultivated Ganoderma lucidum mushrooms for the production of supplements enriched with essential elements. J Food Sci 81:587-592

26. Rzymski P, Mleczek M, Niedzielski P, Siwulski M, Gąsecka M (2017) Cultivation of Agaricus bisporus enriched with selenium, zinc and copper. J Sci Food Agric 97:923-928

27. Mroczek-Zdyrska M, Wójcik M (2012) The influence of selenium on root growth and oxidative stress induced by lead in Vicia faba L. Minor plants. Biol Trace Elem Res 147:320-328

28. Li YF, Zhao J, Li Y, Li H, Zhang J, Li B, Gao Y, Chen C, Luo M, Huang R, Li J (2015) The concentration of selenium matters: a field study on mercury accumulation in rice by selenite treatment in Qingzhen, Guizhou, China. Plant Soil 391:195-205

29. Ismael MA, Elyamine AM, Moussa MG, Cai M, Zhao X, Hu C (2019) Cadmium in plants: uptake, toxicity, and its interactions with selenium fertilizers. Metallomics 11:255-277 
30. Ferrão J, Bell V, Chaquisse E, Garrine C, Fernandes T (2019) The synbiotic role of mushrooms: is germanium a bioactive prebiotic player? A review article. Am J Food Nutr 7:26-35

31. Gonzálvez A, Llorens A, Cervera ML, Armenta S, de la Guardia M (2009) Non-chromatographic speciation of inorganic arsenic in mushrooms by hydride generation atomic fluorescence spectrometry. Food Chem 115:360-364

32. Niedzielski P, Mleczek M, Magdziak Z, Siwulski M, Kozak L (2013) Selected arsenic species: As(III), As(V) and dimethylarsenic acid (DMAA) in Xerocomus badius fruiting bodies. Food Chem 141:3571-3577

33. Kozak L, Rudnicka M, Niedzielski P (2012) Determination of inorganic selenium species in dietary supplements by hyphenated analytical system HPLC-HG-AAS. Food Anal Methods 5:1237-1243

34. Perkowski J, Buśko M, Stuper K, Kostecki M, Matysiak A, Szwajkowska-Michałek L (2008) Concentration of ergosterol in small-grained contaminated and inoculated cereals. Biologia 63:542-547

35. McMahon M, Regan F, Hughes H (2007) The determination of total germanium in real food samples including Chinese herbal remedies using graphite furnace atomic absorption spectroscopy. Food Chem 97:411-417

36. Kolesnikova OP, Tuzova MN, Kozlov VA (1997) Screening of immunoactive properties of alkanecarbonic acid derivatives and germanium-organic compounds in vivo. Immunologiya 10:36-38

37. Tao SH, Bolger PM (1997) Hazard assessment of germanium supplements. Regul Toxicol Pharmacol 25:211-219

38. Tham LX, Matsuhhashi S, Kume T (1999) Growth and fruiting body formation of Ganoderma lucidum on media supplemented with vanadium, selenium and germanium. Mycoscience 40:87-92

39. Puerner NJ, Siegel SM, Siegel BZ (1990) The experimental phytotoxicity of germanium in relation to silicon. Water Air Soil Pollut 49:187-195

40. Halperin S, Barzilay A, Carson M, Roberts C, Lynch J (1995) Germanium accumulation and toxicity in barley. J Plant Nutr 18:1417-1426

41. Ruiz AG, Sola PC, Palmerola NM (2018) Germanium: current and novel recovery processes. In: Lee S (ed) Advanced material and device applications with germanium. InTechOpen, London. https://doi.org/10.5772/intechopen.77997

42. Mleczek M, Magdziak Z, Gąsecka M, Niedzielski P, Kalač P, Siwulski M, Rzymski P, Zalicka S, Sobieralski K (2016) Content of selected elements and low-molecular-weight organic acids in fruiting bodies of edible mushroom Boletus badius (Fr.) Fr. from unpolluted and polluted areas. Environ Sci Pollut Res 23:20609-20618

43. Rentsch L, Aubel I, Schreiter N, Höck M, Bertau M (2016) PhytoGerm: Extraction of germanium from biomass - an economic pre-feasibility study. J Bus Chem 13:47-58

44. Goy A, Kalia A, Sodhi HS (2015) Selenium stress in Ganoderma lucidum: a scanning electron microscopy appraisal. Afr J Microbiol Res 9:855-862

45. Rathore H, Sharma A, Prasad S, Sharma S (2018) Selenium bioaccumulation and associated nutraceutical properties in Calocybe indica mushroom cultivated on Se-enriched wheat straw. J Biosci Bioeng 126:482-487

46. Rayman EP (2012) Selenium and human health. Lancet 379:1256-1268

47. Dogan H, Coteli E, Karatas F (2016) Determination of glutathione, selenium, and malondialdehyde in different edible mushroom species. Biol Trace Elem Res 174:459-463

48. Preda C, Vasiliu I, Bredetean O, Gabriela CD, Ungureanu M-C, Leustean EL, Grigorovici A, Oprisa C, Vulpoi C (2015) Selenium in the environment: essential or toxic to human health? Environ Eng Manag J 15:913-921

49. Mahima A, Kumar A, Verma A, Kumar A, Rahal A, Kumar V, Roy D (2012) Inorganic versus organic selenium supplementation: a review. Pak J Biol Sci 15:418-425

50. Shang D, Li Y, Wang C, Wang X, Yu Z, Fu X (2011) A novel polysaccharide from Se-enriched Ganoderma lucidum induces apoptosis of human breast cancer cells. Oncol Rep 25:267-272

51. Min-Chang G, Wei-Hong T, Zhen X, Jie S (2014) Effects of selenium-enriched protein from Ganoderma lucidum on the levels of IL- $1 \beta$ and TNF- $\alpha$, oxidative stress, and NF- $\kappa$ B activation in ovalbumin-induced asthmatic mice. Evid Based Complement Altern Med 2014:182817

52. Kaur G, Kalia A, Sodhi HS (2017) Selenium biofortification of Pleurotus species and its effect on yield, phytochemical profiles, and protein chemistry of fruiting bodies. J Food Biochem 42:e12467

53. Sułkowska-Ziaja K, Muszyńska B, Szewczyk A (2015) Antioxidant components of selected indigenous edible mushrooms of the obsolete order Aphyllophorales. Rev Iberoam Micol 32:99-102

54. Sławińska A, Fornal E, Radzki W, Skrzypczak K, ZalewskaKorona M, Michalak-Majewska M, Parfieniuk E, Stachniuk A (2016) Study on vitamin D2 stability in dried mushrooms during drying and storage. Food Chem 199:203-209

55. Vieira FPA, Gontijo DC, Vieira BC, Fontes EAF, De Assunção LS, Leite JPV, Oliveira MGA, Kasuya MCM (2013) Antioxidant activities, total phenolics and metal contents in Pleurotus ostreatus mushrooms enriched with iron, zinc or lithium. LWT Food Sci Technol 54:421-425

56. Tripkovic L, Lambert H, Hart K, Smith CP, Bucca G, Penson S, Chope G, Hyppönen E, Berry J, Vieth R, Lanham-New S (2012) Comparison of vitamin D2 and vitamin D3 supplementation in raising serum 25-hydroxyvitamin D status: a systematic review and meta-analysis. Am J Clin Nutr 95:1357-1364

57. Rodrigues ML (2018) The multifunctional fungal ergosterol. mBio 9:e01755-18

58. Montenegro L, Bonina F, Dederen JC (1997) In vivo protective effect of $\beta$-bis-(carboxyethyl)germanium sesquioxide. J Soc Cosmet Chem 47:307-313

59. Schauss AG (1991) Nephrotoxicity in humans by the ultratrace element germanium. Ren Fail 13:1-4

60. Wu CM, Matsuoka T, Takemitsu M, Goto Y, Nonaka I (1992) An experimental model of mitochondrial myopathy: germaniuminduced myopathy and coenzyme Q10 administration. Muscle Nerve 15:1258-1264

61. Sanai T, Okuda S, Onoyama K, Oochi N, Oh Y, Kobayashi K, Shimamatsu K, Fujimi S, Fujishima M (1990) Germanium dioxide-induced nephropathy: a new type of renal disease. Nephron 54:53-60

62. Makinistian L, Albanesi EA (2007) Ab initio calculations of the electronic and optical properties of germanium selenide. J Phys Condens Matter 19:186211

63. Anger FS, Anger JP, Sado PA, Chevanne F (1994) Absolute and relative bioavailability of germanium in the rabbit. J Pharm Belg 49:395-401

Publisher's Note Springer Nature remains neutral with regard to jurisdictional claims in published maps and institutional affiliations. 